\title{
Analytical solution of integro-differential equations describing the process of intense boiling of a superheated liquid
}

\author{
Irina Alexandrova ${ }^{1}$, Alexander Ivanov $^{1}$, and Dmitri Alexandrov ${ }^{1}$ \\ ${ }^{1}$ Ural Federal University named after the first President of Russia B N Yeltsin
}

February 28, 2021

\begin{abstract}
In this article, an approximate analytical solution of an integro-differential system of equations is constructed, which describes the process of intense boiling of a superheated liquid. The kinetic and balance equations for the bubble-size distribution function and liquid temperature are solved analytically using the Laplace transform and saddle-point methods with allowance for an arbitrary dependence of the bubble growth rate on temperature. The rate of bubble appearance therewith is considered in accordance with the Dering-Volmer and Frenkel-Zeldovich-Kagan nucleation theories. It is shown that the initial distribution function decreases with increasing the dimensionless size of bubbles and shifts to their greater values with time.
\end{abstract}

\section{Hosted file}

wileyNJD-AMA_paper sent.pdf available at https://authorea.com/users/339752/articles/511279analytical-solution-of-integro-differential-equations-describing-the-process-of-intenseboiling-of-a-superheated-liquid

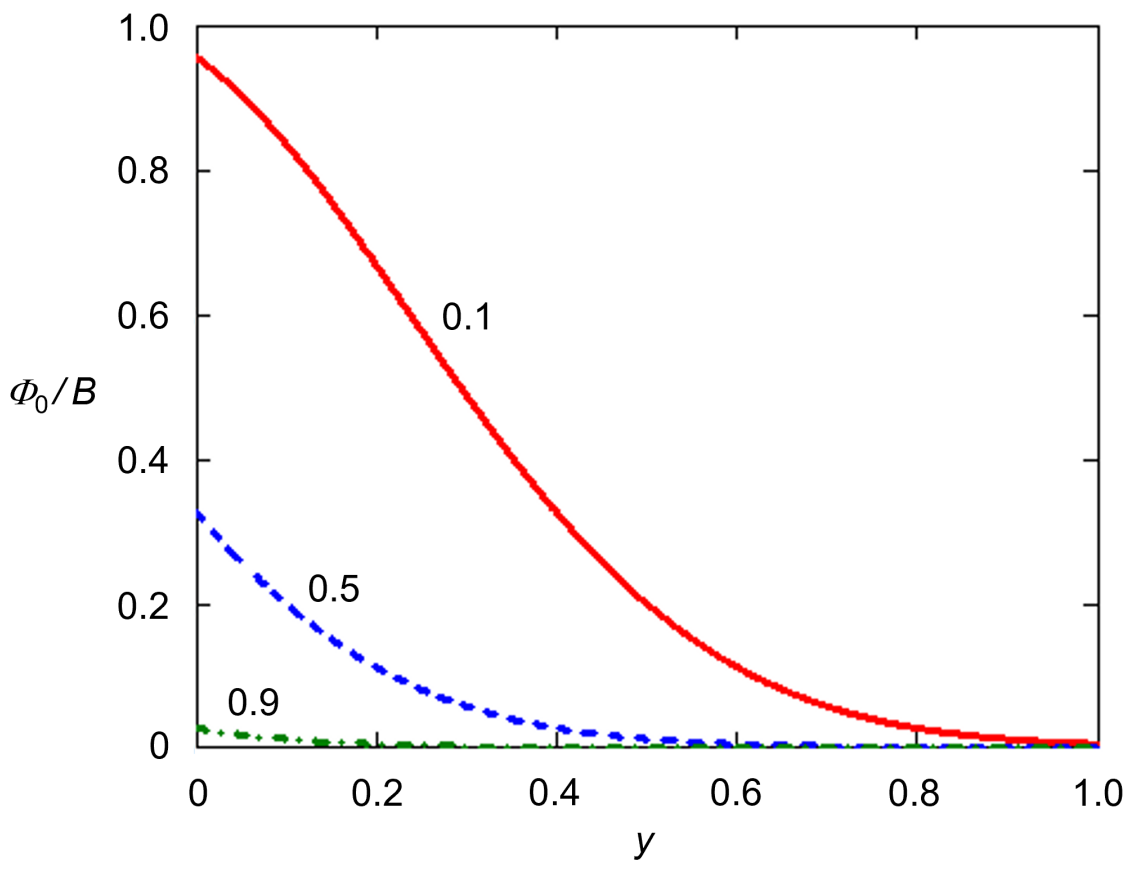



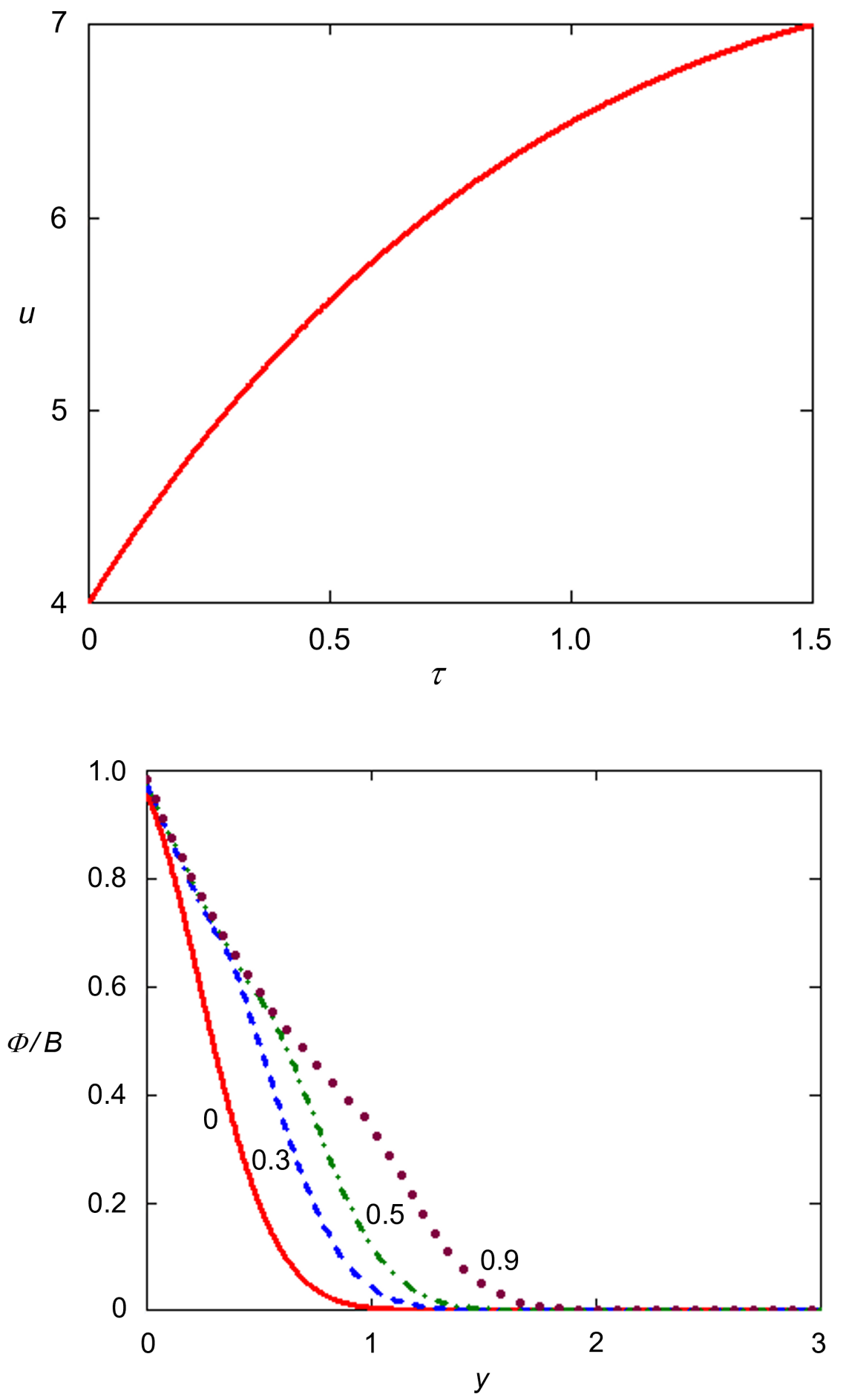